\title{
Left Ventricular Aneurysm Presenting as Bidirectional Ventricular Tachycardia
}

\author{
Abdulah Alrifai, MD, Mohamad Kabach, MD, Jonathan Nieves, MD, Robert Chait, MD \\ Department of Cardiology, University of Miami/JFK Medical Center, Atlantis, FL
}

Background: Bidirectional ventricular tachycardia is a rare form of ventricular arrhythmia, characterized by a changing of the mean QRS axis of 180 degrees. Digitalis toxicity is the most common cause of bidirectional ventricular tachycardia; other causes include myocarditis, aconite toxicity, metastatic cardiac tumor, myocardial infarction, and cardiac channelopathies.

Case Report: A 73-year-old male with hypertension and a pacemaker implanted for sick sinus syndrome presented with a complaint of substernal chest pressure for several days. He also stated he had had an episode of near syncope. The patient's physical examination was unremarkable; however, electrocardiogram demonstrated sustained bidirectional ventricular tachycardia. Echocardiogram showed severe anterior wall hypokinesis and an estimated ejection fraction of $35 \%$, as well as an apical ventricular aneurysm. Electrophysiology study showed that the apical ventricular aneurysm was the site of the bidirectional arrhythmia. The patient was successfully treated with ventricular tachycardia ablation.

Conclusion: This case is a unique example of a patient with bidirectional ventricular tachycardia originating from an apical left ventricular aneurysm that was treated successfully by ablation.

Keywords: Bidirectional ventricular tachycardia, heart aneurysm, tachycardia-ventricular

Address correspondence to Abdulah Alrifai, MD, Department of Cardiology, University of Miami/JFK Medical Center, 5301 South Congress Ave., Atlantis, FL 33462. Tel: (561) 548-1538. Email: abd.rifai@gmail.com

\section{INTRODUCTION}

Bidirectional ventricular tachycardia is a rare form of polymorphic ventricular tachycardia, characterized by beat-tobeat alternation of the QRS axis of 180 degrees. The rate is typically $140-180 \mathrm{bpm}$. The most common cause of bidirectional ventricular tachycardia is digitalis toxicity. ${ }^{1}$ Other etiologies include myocarditis, aconite toxicity, long QT syndrome type $7,{ }^{2}$ metastatic cardiac tumor, acute cardiac allograft rejection, and myocardial infarction. ${ }^{3}$ We report a case of bidirectional ventricular tachycardia emanating from a left ventricular aneurysm.

\section{CASE REPORT}

A 73-year-old male with a medical history significant for hypertension and a permanent pacemaker for sick sinus syndrome was admitted to the hospital with a complaint of several days of substernal chest pressure and an episode of near syncope. Except for his heart rate, the patient's vital signs were stable, with no evidence of hemodynamic instability. Physical examination was unremarkable. Laboratory studies did not reveal any significant abnormality. Electrocardiogram performed in the emergency department demonstrated sustained bidirectional ventricular tachycardia (Figure 1). Treatment with a $150 \mathrm{mg}$ intravenous bolus of amiodarone followed by a constant infusion resulted in a return to normal sinus rhythm within 6 hours. Echocardiogram revealed severe anterior wall hypokinesis with an estimated ejection fraction of $35 \%$ and an apical ventricular aneurysm (Figure 2). Cardiac angiography demonstrated severe stenosis in the proximal left anterior descending, left circumflex, and proximal right coronary arteries. Based on the patient's anatomy, multiple comorbidities, and high surgical risk, he was deemed a poor candidate for either percutaneous coronary intervention or bypass surgery. His hospitalization was complicated by recurrent runs of sustained bidirectional ventricular tachycardia. Electrophysiology study showed that the apical ventricular aneurysm was the source of the bidirectional arrhythmia. Based on the findings, ventricular tachycardia ablation was performed successfully. The patient was discharged home on amiodarone $200 \mathrm{mg}$ twice daily and carvedilol $25 \mathrm{mg}$ once daily. When the patient was evaluated at 6 months, pacemaker interrogation did not reveal a recurrence of sustained ventricular tachycardia.

\section{DISCUSSION}

This case presents a unique scenario in which a rare arrhythmia known to be a hallmark of severe digitalis toxicity was found to originate from a major distortion of the left ventricular architecture. We believe that the patient had had a myocardial infarction that led to ventricular aneurysm formation and then to the subsequent arrhythmia. Although ventricular aneurysms have been known to provide a focus for 


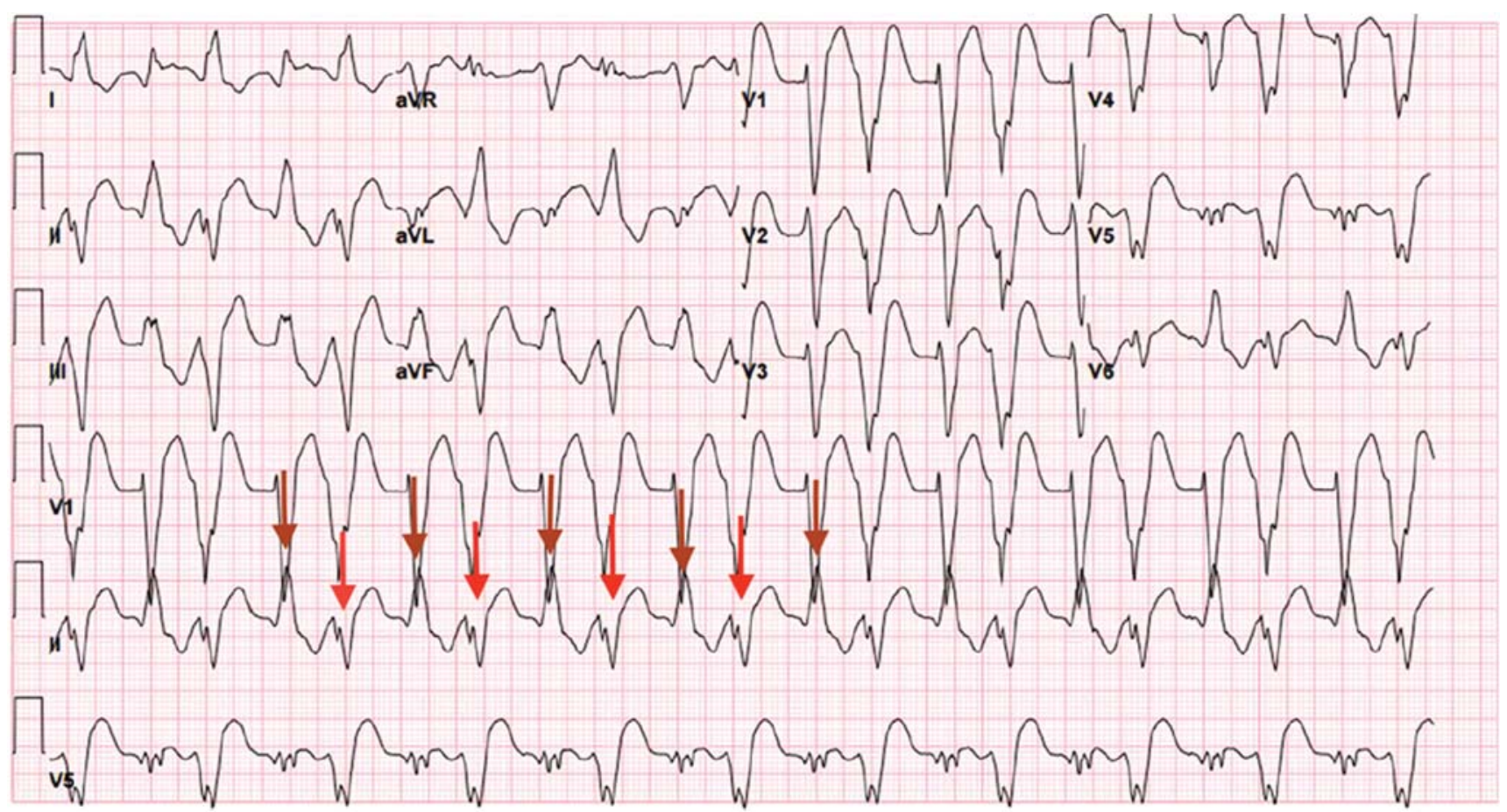

Figure 1. Bidirectional ventricular tachycardia. Note the alternating QRS axes and bundle branch block morphology.

both monomorphic and polymorphic ventricular tachycardia, ${ }^{4}$ to our knowledge, no reports of an aneurysm being the site of origin of a bidirectional ventricular tachycardia have been published. Cases have been reported, however, of bidirectional ventricular tachycardia occurring shortly after myocardial infarction ${ }^{5}$ or in association with infiltrative cardiomyopathies such as sarcoidosis. ${ }^{6}$
Bidirectional ventricular tachycardia can be associated with catecholaminergic polymorphic ventricular tachycardia, also known as familial polymorphic ventricular tachycardia, a syndrome resulting from inherited abnormalities of myocardial cell calcium channels. ${ }^{7}$ Believed to be caused by RyR2 and CASQ2 gene mutations, catecholaminergic polymorphic ventricular tachycardia is usually diagnosed in the

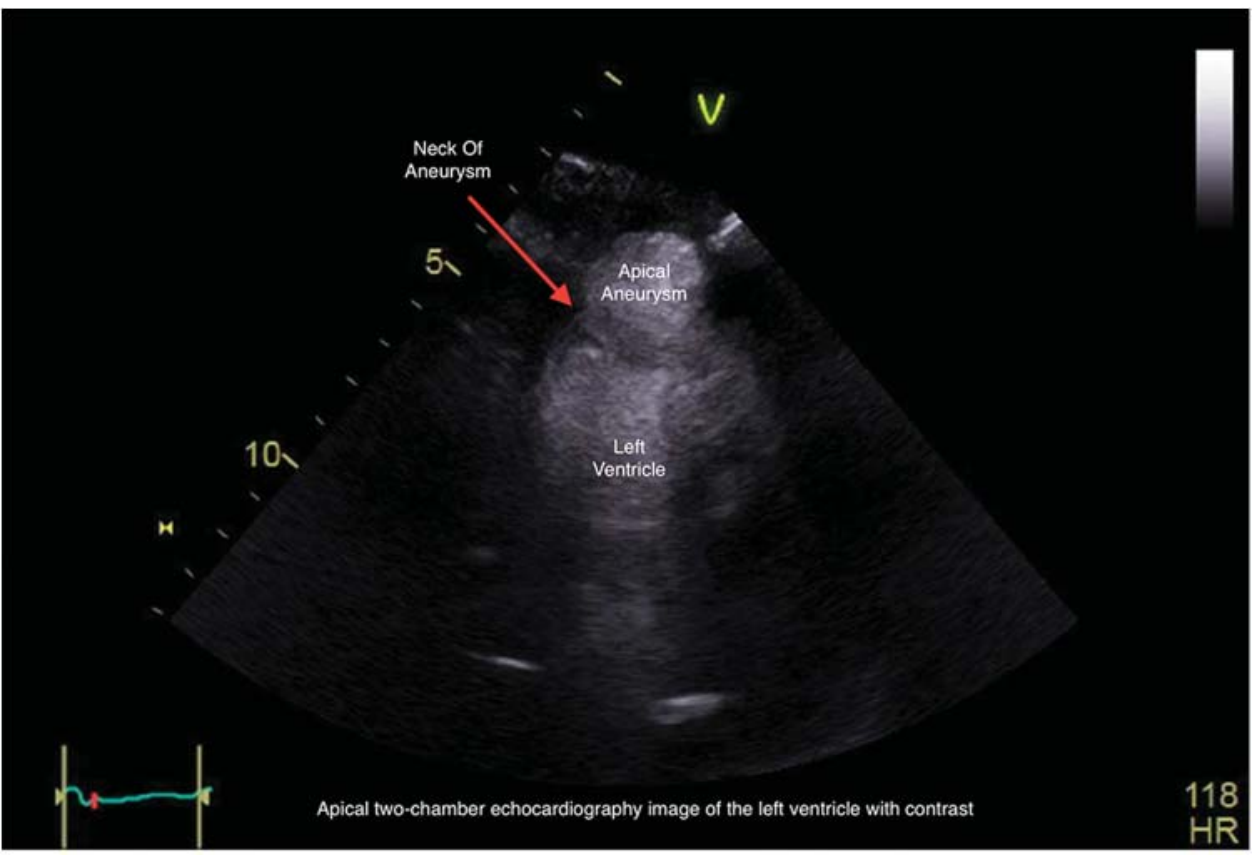

Figure 2. Transthoracic 2-dimensional echocardiogram with contrast showing apical left ventricular aneurysm. 
pediatric population and tends to occur under adrenergic stimulation (eg, during exercise or stress). ${ }^{8}$ Moreover, torsades de pointes can occur with congenital or acquired long QT syndrome ${ }^{9}$ and should be considered in the differential diagnosis of polymorphic ventricular arrhythmia.

In the absence of inherited myocardial channelopathies, bidirectional ventricular tachycardia has long been associated with digitalis toxicity. Although the exact mechanism of bidirectional ventricular tachycardia is unclear, evidence from human and animal electrophysiologic studies has shown that alternating ectopic foci originating from the distal His-Purkinje system in either or both ventricles may be the cause of the arrhythmia. ${ }^{10}$ The mechanism is thought to be secondary to delayed after-depolarization in phase 4 of the myocyte action potential. Patients who present with this arrhythmia should be evaluated for drug toxicity, metabolic derangements, and potential genetic etiologies. Furthermore, based on this case, investigation should also include consideration of potential alterations in ventricular architecture.

\section{CONCLUSION}

We present a rare case of bidirectional ventricular tachycardia originating from an apical left ventricular aneurysm that was treated successfully by ablation.

\section{ACKNOWLEDGMENTS}

The authors have no financial or proprietary interest in the subject matter of this article.

\section{REFERENCES}

1. Schwensen E. Ventricular tachycardia as a result of the administration of digitalis. Heart (Br Card Soc). 1922;9:199.
2. Sumitomo N, Shimizu W, Taniguchi K, Hiraoka M. Calcium channel blocker and adenosine triphosphate terminate bidirectional ventricular tachycardia in a patient with Andersen-Tawil syndrome. Heart Rhythm. 2008 Mar;5(8):498499. doi: 10.1016/j.hrthm.2007.12.012.

3. Sonmez O, Gul EE, Duman C, Düzenli MA, Tokaç M, Cooper J. Type II bidirectional ventricular tachycardia in a patient with myocardial infarction. J Electrocardiol. 2009 Nov-Dec;42(6):631632. doi: 10.1016/j.jelectrocard.2009.06.011.

4. Izawa A, Yazaki Y, Hayashi S, Imamura H, Kusama Y, Isobe M. Transient left ventricular aneurysm and hypertrophy accompanied by polymorphic ventricular tachycardia in a patient suspected of acute myocarditis. Jpn Heart J. 2000 Jan;41 (1):97-102.

5. Wase A, Masood AM, Garikipati NV, Mufti O, Kabir A. Bidirectional ventricular tachycardia with myocardial infarction: a case report with insight on mechanism and treatment. Indian Heart J. 2014 Jul-Aug;66(4):466-469. doi: 10.1016/j.ihj.2014.05.024.

6. Benjamin MM, Hayes K, Field ME, Scheinman MM, Hoffmayer KS. Bidirectional ventricular tachycardia in cardiac sarcoidosis. J Arrhythm. 2017 Feb;33(1):69-72. doi: 10.1016/j.joa.2016.05.003.

7. Roston TM, Vinocur JM, Maginot KR, et al. Catecholaminergic polymorphic ventricular tachycardia in children: analysis of therapeutic strategies and outcomes from an international multicenter registry. Circ Arrhythm Electrophysiol. 2015 Jun;8 (3):633-642. doi: 10.1161/CIRCEP.114.002217.

8. Kontula K, Laitinen PJ, Lehtonen A, Toivonen L, Viitasalo M, Swan H. Catecholaminergic polymorphic ventricular tachycardia: recent mechanistic insights. Cardiovasc Res. 2005 Aug;67(3):379-387.

9. Yap YG, Camm AJ. Drug induced QT prolongation and torsades de pointes. Heart. 2003 Nov;89(11):1363-1372.

10. Baher AA, Uy M, Xie F, Garfinkel A, Qu Z, Weiss JN. Bidirectional ventricular tachycardia: ping pong in the His-Purkinje system. Heart Rhythm. 2011 Apr;8(4):599-605. doi: 10.1016/j.hrthm.2010 .11 .038 .

This article meets the Accreditation Council for Graduate Medical Education and the American Board of Medical Specialties Maintenance of Certification competencies for Patient Care and Medical Knowledge. 